\title{
A INTELIGÊNCIA EMOCIONAL NO ÂMBITO ACADÊMICO: Uma aproximação teórica e empírica
}

\author{
Emotional intelligence in the academic environment: \\ A theoretical and empirical approach
}

\author{
Nair Floresta Andrade Neta ${ }^{a}$, Emilio García García ${ }^{b}$, Isabel Santos Gargallo ${ }^{c}$ \\ a Professora Assistente de Espanhol/LE da Universidade Estadual de Santa Cruz (UESC), Mestre em Ensino do Espanhol como \\ Língua Estrangeira (Universidade de Alcalá-UA), Madrid - España, e-mail: nairandrade@hotmail.com \\ b Professor Titular de Psicologia Básica da Universidade Complutense de Madrid (UCM), Madrid - Epanha, e-mail: \\ emiliogar@uol.com.br \\ c Professor Titular de Psicologia Básica da Universidade Complutense de Madrid (UCM), Professora Dr. ${ }^{a}$ Titular do Departamento \\ de Didática da Língua, da Universidade Complutense de Madrid (UCM). Madrid - Espanha, e-mail: isabelsantosg@hotmail.com
}

\begin{abstract}
Resumo
O conceito de Inteligência Emocional surgiu em 1990, proposto pelos pesquisadores Peter Salovey e John Mayer. No entanto, tornou-se conhecido mundialmente após a publicação do livro Inteligência Emocional, em 1995, por Daniel Goleman. Desde então, além do interesse popular gerado, o construto também provocou certo "rebuliço" no âmbito científico. Para compreender alguns aspectos dessa polêmica, a primeira parte deste artigo apresenta uma aproximação teórica ao novo construto, relacionando-o com perspectivas teóricas acerca da inteligência e da emoção, situando a inteligência emocional no bojo das propostas alternativas à definição e compreensão clássica da inteligência humana. A segunda parte apresenta os resultados de um trabalho de pesquisa, divulgado no I Congresso de Inteligência Emocional (realizado em 2007, Málaga-Espanha), que consistiu em analisar sistematicamente uma parte da produção acadêmica proveniente dos cursos de pós-graduação stricto sensu (Mestrado Profissional, Mestrado Acadêmico e Doutorado) do Brasil, para averiguar que interesse científico o construto da Inteligência Emocional despertou no âmbito acadêmico brasileiro. Foram revisados os resumos de teses e dissertações, registrados no Banco de Teses da CAPES, abarcando o período de 1990 a 2006. A freqüente afirmação de que "o interesse científico pela inteligência emocional tem sido crescente" não se evidencia com relação à produção acadêmica analisada. Os resultados desse trabalho exploratório mostram a existência de um descontínuo interesse científico pelo novo construto nos cursos de pós-graduação do Brasil.
\end{abstract}

Palavras-chave: Inteligência emocional; Pesquisa exploratória; Pós-graduação; Brasil. 


\begin{abstract}
Emotional Intelligence as a concept came up in 1990 suggested by researchers Meter Salovey and John Mayer. Though it was not until the publication of Daniel Goleman's book Emotional Intelligence in 1995 that it came to be worlwide known. Since then, besides the popular interest, the new construct have caused some kind of commotion in the scientific field. So as to understand some aspects of this controversy, the first part of the article presents a theoretical approximation to the new construct related to theoretical perspectives about intelligence and emotion situating emotional intelligence in the center of the alternative proposals to a definition and a classical comprehension of human intelligence. The second part brings the results of a research work brought out in the I Congress on Emotinal Intelligence (hold in 2007 in Malaga-Spain), in which a part of the academic production belonging to the strictu sensu post graduation courses from Brazil (Professional Masters, Academic Masters and Doctorates) is sistematically analysed aiming to find out the scientific interest promoted by the Emotional Intelligence construct in the Brazilian academic enviroment. The abstracts of theses and dissertations registered from 1990 to 2006 in the CAPES Bank of Theses were ckecked. The frequent statement "the scientific interest on emotional intelligence has been increasing" does not prove evident in the analysed academic production. The results of this exploratory work show the existence of a discontinuous scientific interest on the new construct in the post-graduation courses in Brazil.
\end{abstract}

Keywords: Emotional intelligence; Exploratory research; Post-graduation; Brazil

\section{INTRODUÇÃO}

O conceito de Inteligência Emocional (IE) surgiu no âmbito acadêmico, em 1990, formalizado pelos pesquisadores Peter Salovey (Yale University) e John Mayer (University of New Hampshire), que introduziram o termo na literatura científica por meio de dois artigos (Mayer, DiPaolo \& Salovey, 1990). Na primeira publicação, de natureza teórica, os autores propuseram uma definição inicial de inteligência emocional como sendo "a habilidade para controlar os sentimentos e emoções em si mesmo e nos demais, discriminar entre elas e usar essa informação para guiar as ações e os pensamentos" (Mayer, DiPaolo, \& Salovey, 1990, p. 189). O segundo artigo ofereceu as primeiras demonstrações empíricas de como a inteligência emocional poderia ser considerada como uma habilidade mental.

Apesar de ter se originado na comunidade acadêmica - ou talvez por isso -, o novo conceito passou praticamente inadvertido, até que, em 1995, o psicólogo e redator científico Goleman (1995) publicou o livro, que viria a ser um bestseller mundial, intitulado Inteligência Emocional. Apoiando-se em pesquisas sobre o cérebro, as emoções e a conduta, o autor explana, em linguagem acessível e persuasiva, as concepções em torno da inteligência de tipo emocional e, baseando-se no conceito inicialmente formulado por Mayer e Salovey (1990), concebe uma perspectiva mais ampla de IE, acrescentando, às habilidades cognitivas, vários atributos da personalidade. Para Goleman (1995), a IE inclui características como a capacidade de motivar a si mesmo, de perseverar no empenho apesar das frustrações, de controlar os impulsos, de adiar as gratificações, de regular os próprios estados de ânimo, de evitar a interferência da angústia nas faculdades racionais, de sentir empatia, de confiar nos demais, etc. Apesar do apanhado de concepções teóricas bem comentadas ao longo da obra, das histórias ilustrativas usadas, das abundantes referências científicas e das explicações sobre a IE, a nosso ver, Goleman (1995), nessa ocasião, não oferece uma definição conceitual clara de inteligência emocional.

Essa expansão do conceito, embora amplamente difundida popularmente, tem recebido muitas críticas no âmbito científico. Nesse sentido, Mayer, Salovey e Caruso (2002) criticam o uso do termo inteligência emocional para fazer alusão a áreas amplas da personalidade, que vão além da emocional e da cognitiva. Também julgam 
inadequado considerar a teoria de Goleman como científica, posto que, segundo os pioneiros do conceito, ela "foi inicialmente apresentada como uma narrativa jornalística de [sua] própria teoria [de Salovey e Mayer]" (Mayer, Salovery \& Caruso, 2002 , p. 88), não apresentando nenhuma contribuição ou formulação teórica própria. Da mesma forma, Hedlund e Sternberg (2002) consideram que uma das limitações do uso que Goleman faz do termo inteligência emocional consiste no fato de ele incluir, dentro desse construto, tudo o que não seja o Q.I. Igualmente, esses autores defendem que o trabalho de Goleman está fundamentalmente embasado em "evidências anedóticas e extrapolações questionáveis de pesquisas passadas" (Hedlund \& Sternberg, 2002, p. 118).

Navas e Berrocal (2007) destacam duas conseqüências do trabalho de Goleman: uma positiva e outra negativa. Por um lado, o exxito do best-seller dinamizou e favoreceu o interesse pela IE, mas, por outro, tergiversou em certa medida as idéias de Salovey \& Mayer (1990), desviando o conceito para o campo dos traços da personalidade. Segundo Mestre (2003), as habilidades sociais e pessoais que Goleman (1995) inclui em sua proposta de IE são tantas e tão abrangentes que configurariam a um ser humano perfeito, cujo perfil, obviamente, seria garantia de êxito.

Em defesa de sua proposta integradora da inteligência emocional, Boyatzis, Goleman e Rhee (2002, p. 253) sustentam que "se for definido como um conceito único, o termo inteligência emocionalpode ser ilusório e sugerir uma associação com a capacidade cognitiva tradicionalmente definida [fator g]." Argumentam que um conceito integrador seria ideal para oferecer um modelo teórico para a organização da personalidade e para a conexão entre a inteligência emocional e uma teoria de ação e desempenho no trabalho.

O interesse deflagrado pela propagação do termo inteligência emocional mobilizou também os criadores do construto que, preocupados com a variedade de definições, reinvenções e reivindicações da importância do conceito, tomaram algumas medidas cautelares no sentido de preservar o cientificismo da IE. Assim sendo, revisaram e clarificaram o conceito primitivo e estabeleceram uma nomenclatura para diferenciar os Modelos de Inteligência Emocional centrados nas habilidades cognitivas (modelos de aptidões on habilidades) daqueles que incluíssem traços de personalidade, fatores motivacionais ou outros (modelos mistos). Os primeiros são, portanto, mais restritos e os segundos, mais abrangentes.

$\mathrm{Na}$ revisão conceitual, Mayer e Salovey (2007) procuraram focalizar a IE como um conjunto de aptidões, capacidades ou habilidades mentais, aproximando-a mais do campo de estudos da inteligência. A IE passa a ser definida, mais precisamente, em termos de quatro grupos de habilidades relacionadas:

A inteligência emocional implica a habilidade para perceber e valorar com exatidão a emoção; a habilidade para acessar e ou gerar sentimentos quando esses facilitam o pensamento; a habilidade para compreender a emoção e o conhecimento emocional, e a habilidade para regular as emoções que promovem o crescimento emocional e intelectual (Mayer \& Salovey, 1997/2007, p. 32).

A percepção e identificação emocional se referem à habilidade para perceber e identificar as emoções próprias e alheias, incluindo na voz das pessoas, nas obras de arte, na música, nas histórias. O segundo componente, a facilitação emocional, envolve a habilidade para usar as emoções para facilitar os processos cognitivos (na solução de problemas, tomada de decisões, relações interpessoais). Compreender a emoção implica conhecer os termos relacionados com as emoções e as formas como estas se combinam, progridem e mudam. O último nível, o de regulação emocional, trata da habilidade de saber usar estratégias para mudar os próprios sentimentos e saber avaliar se elas são eficazes ou não. Mayer e Salovey (2007) crêem que essa definição atualizada consegue unir as idéias de que a emoção nos faz pensar mais inteligentemente e, por outro lado, pensamos inteligentemente sobre as emoções.

O Modelo de Inteligência Emocional como Aptidão (Salovey \& Mayer, 1990; Mayer \& Salovey, 2007) coexiste com o Modelo de Competências Emocionais (Goleman, 1995), Modelo de Inteligência Social e Emocional (BarOn, 1997) e, com menor expressividade, com o Modelo de Cooper e Sawaf (1997). Embora a proposta de Goleman seja a mais divulgada, no ámbito acadêmico o Modelo de Aptidões tem sido considerado como autêntico modelo explicativo da IE (Mestre, 2003) e tem se consolidado na Psicologia como modelo de referência para as 
pesquisas na área devido ao rigor teórico e empírico, tanto no que se refere à formalização conceitual, quanto aos instrumentos de medida de auto-informe e de execução, cujas experimentações têm aumentado seu índice de fiabilidade; também tem sido considerado como o mais factível para o desenvolvimento de programas de intervenção (Pacheco \& Berrocal, 2005).

A elucidação do construto da IE tem ocorrido de forma paulatina, porém constante. A aceitação do seu status de inteligência ainda encontra muitas resistências, mas também tem recebido muito apoio científico. A esse respeito, Bechara, Tranel e Damasio (2002, p. 163) prestam uma inestimável contribuição à compreensão das evidências neurológicas da IE, partindo dos resultados das pesquisas em pacientes com lesões bilaterais do córtex pré-frontal ventro-mediano. Tais descobertas demonstram a influência das emoções nas funções cognitivas e comportamentais do indivíduo, incluindo a memória e a tomada de decisão, e dão um bom exemplo de que possuir conhecimentos e um Q.I. elevado não bastam para que as decisões tomadas pela pessoa representem escolhas vantajosas para sua vida pessoal e social. De acordo com esses pesquisadores, o prejuízo na capacidade de lidar eficazmente com as exigências sociais e ambientais, observado na conduta dos pacientes estudados, deve-se a um déficit na sua habilidade de processamento de sinais emocionais. Para eles, "isso proporciona amplas evidências para a noção de que as emoções são os ingredientes de uma forma distinta de capacidade, que é crítica para a inteligência global na vida social" Bechara et al. (2002, p. 162). Encerram sua colaboração com uma conclusão afiançadora:

Nossos estudos de pacientes neurológicos não defendem um modelo de inteligência emocional em detrimento de outro. Entretanto, nossas pesquisas proporcionam fortes evidências para o principal conceito de inteligência emocional, a qual pode ser vista como um conjunto de aptidões emocionais que constituem uma forma de inteligência diferente da inteligência cognitiva ou do QI. Essa inteligência emocional faz com o indivíduo seja socialmente mais eficaz em certos aspectos da vida do que outros indivíduos.

Essa afirmação cobra especial relevância considerando-se a grande contribuição que a Neurociência tem proporcionado à elucidação das emoções e dos sentimentos na mente humana. O avanço das pesquisas de Damásio e colaboradores evidenciaram que as emoções e os sentimentos não só podem ser abordados, medidos, explicados e compreendidos cientificamente, como também podem ser distinguidos neurobiologicamente. Em função dessa descoberta, Damásio $(1996,2000,2004)$ usa de forma distinta os dois termos. O termo emoção fica reservado para referir-se ao "conjunto de mudanças que ocorrem quer no corpo, quer no cérebro e que normalmente é originado por um determinado conteúdo mental" (Damasio, 1996, p. 301), enquanto o termo sentimento é usado para referir-se à percepção dessas mudanças. De acordo com essa teoria, "ao contrário da opinião científica tradicional, [as emoções e os sentimentos] são tão cognitivos como qualquer outra percepção" (Damasio, 1996, p. 15). Outro aspecto da pesquisa de Damásio que precisa ser melhor apreciado pelos estudiosos da IE é a relação entre as emoções e a consciência. As emoções são componentes essenciais do kit de sobrevivência com o qual nascemos equipados. Nós, humanos, além das emoções, podemos ser capazes de ter sentimentos e de saber que os temos. Esse saber que temos sentimentos só é possível porque temos consciência. Segundo Damásio (2000, p. 80), "a consciência permite que os sentimentos sejam conhecidos e, assim, promove internamente o impacto da emoção, permite que ela, por intermédio do sentimento, permeie o processo do pensamento". Para Damásio, tanto a emoção como a consciência estão ligadas à sobrevivência do organismo. Em outras palavras, a consciência amplia a proteção proporcionada pelo nosso kit de sobrevivência. Acreditamos que essa relação entre emoção e consciência é especialmente importante para explicar a habilidade de administrar ou regular as emoções.

Todas essas contribuições da neurociência têm proporcionado uma visão mais conciliadora e integradora às clássicas dicotomias razão versus paixão, pensamento versus sentimento, cabeça versus coração, cognição versus emoção... Termos como conciliar e integrar merecem ser ressaltados nessa fase da pesquisa no campo da IE. A constatação de que "a cognição não é tão lógica como se pensava outrora, e nem sempre as emoções são tão irracionais" (LeDoux, 2001, p. 33) não deve 
conduzir a outro antagonismo: inteligência emocional versus inteligência cognitiva. Às vezes, as discussões sobre a natureza da inteligência, incluída a emocional, tendem a sugerir uma substituição de inteligências ou uma alternância de posição de supremacia. Essa advertência será mais bem compreendida nos parágrafos seguintes, especialmente quando fazemos referência à "metáfora do elefante".

O construto da IE une dois complexos campos de estudo que têm uma larga história na Psicologia. Apesar da abundante produção científica das duas áreas de conhecimento, ambas têm questões cruciais a serem esclarecidas acerca da natureza de seus respectivos objetos principais de estudo: a inteligência e a emoção. Sobre a emoção já foram apresentadas algumas relevantes e atuais considerações para justificar o uso do termo emocional na configuração da inteligência em análise. Segundo LeDoux (2001, p. 22), “os cientistas não estão conseguindo chegar a um acordo quanto ao que sejam as emoções"; mas essa falta de consenso não impede o avanço da pesquisa em IE. E quanto à inteligência? Para situar a IE nesse campo, faremos uma digressão nos próximos parágrafos para tratar da inteligência.

Em dois históricos momentos, em 1921 e em 1986, pesquisadores de reconhecido prestígio no âmbito da Psicologia foram convidados a responderem à pergunta: $O$ que é a inteligência?'

Além de emitirem seu parecer acerca do conceito de inteligência e a melhor forma de medi-la por testes coletivos, os psicólogos selecionados deveriam indicar futuras direções para a pesquisa na área em debate. Contrastando os dois simpósios, as conclusões são as seguintes: a) o campo de estudo da inteligência evoluiu, passando de uma atenção primordial aos aspectos psicométricos a um interesse maior pelo processamento da informação, o contex to cultural e a interação entre ambos; b) a compreensão da conduta inteligente passou a ser mais importante do que a sua predição; c) houve avanço quanto à compreensão das bases cognitivas e culturais relacionadas com os resultados dos testes de Q.I.; d) as definições de inteligência estão mais bem elaboradas, apesar de não haver consenso na aceitação de uma delas; e) o estudo da inteligência se situa num contexto social mais amplo; $\mathrm{f}$ ) houve pouco avanço, se é que realmente se avançou, quanto aos problemas relativos à natureza da inteligência, e continua preocupando o dilema da unicidade frente à multiplicidade (Sternberg \& Berg, 2003; Detterman, 2003).

Duas décadas depois da realização do segundo simpósio, continuam os esforços por conseguir definir "um construto escorregadio em um campo escorregadio: o da inteligência" (Sternberg \& Detterman, 2003, p. 16). Segundo Horn (2003), em sua participação no segundo simpósio, a quase inutilidade das tentativas de descrever a inteligência se deve à insistência em tratá-la como uma "entidade unitária", quando os conhecimentos disponíveis na atualidade lhe sugeriam que o termo inteligência denota uma mistura de fenômenos importantes. Segundo ele, para entender essa "mistura confusa", a investigação devia partir daquilo que já se conhece. E o que se conhece:

Aponta para uma idéia da capacidade intelectual humana como algo integrado por diferentes "inteligências", que têm diferentes determinantes genéticos e ambientais, que estão a serviço de diferentes funções da personalidade, que se baseiam em histórias filogenéticas e ontogenéticas distintas e que se relacionam de modo diferente com as predições dos resultados profissionais, educativos, adaptativos e de ajuste. (Horn, 2003, p. 113).

Nesse sentido, a inteligência emocional surge como uma forma alternativa de explicação à natureza da inteligência, integrando-se ao grupo das habilidades mentais consideradas emergentes. Essas habilidades emergem das teorias que têm reivindicado uma reformulação da compreensão

\footnotetext{
Em 1921, o simpósio foi organizado e publicado pelos editores do The Journal of Educational Psychology. Participaram dessa etapa catorze eminentes psicólogos, pesquisadores da inteligência, sobretudo do campo da Psicologia da Educação. Em 1986, o simpósio foi atualizado em forma de livro, sob a organização dos pesquisadores R. J. Sternberg e D. K. Detterman (2003). Nessa ocasião, colaboraram vinte e quatro especialistas no tema, oriundos de diversas áreas de pesquisa da Psicologia: Educacional, Cognitiva, Transcultural, Evolutiva, Sociologia, Psicometria, Genética da Conduta, etc. Em ambas as ocasiões, os pesquisadores deveriam tratar de duas questões básicas: 1. O que é a "inteligência" e qual a melhor forma de medi-la mediante testes coletivos? 2. Quais devem ser os "seguintes passos" mais importantes na pesquisa sobre a inteligência?
} 
clássica da inteligência como uma capacidade geral, comumente designada fator $g$, que pode ser medida em algumas horas, pelos testes de Q.I., aferindo conhecimentos lingüísticos, lógico-matemáticos e espaciais. No entanto, as propostas alternativas de inteligência demonstram que o Q.I. pode ser muito eficaz para predizer o sucesso acadêmico (mede a inteligência acadêmica), mas não garante o êxito na vida real. Sternberg (1997, p. 24-25), um dos mais reconhecidos representantes contemporâneos da pesquisa em inteligência, diz que "a idéia de relacionar o coeficiente intelectual com os logros na vida é uma idéia descabelada, pois o coeficiente intelectual é um elemento pobríssimo de predição dos logros na vida”. Partindo dessas constatações, os pesquisadores emergentes desse movimento científico de reforma das concep̧̧ões de inteligência bumana têm sugerido definições menos restritas, enfatizando a natureza multifacetada da inteligência humana. Para marcar essa oposição à unicidade conceitual, os teóricos têm adotado o uso de qualificativos que enfatizam o aspecto que se prioriza em sua concepção de inteligência. Nesse elenco de inteligências emergentes destacam-se a inteligência prática, exitosa, plena (Sternberg, 1985, 1997), as inteligências múltiplas (Gardner, 1983) e a inteligência emocional (Salovey \& Mayer, 1990; Goleman, 1995; Bar-On, 1997). Embora essas propostas representem abordagens diferentes, compartem alguns pontos de vista: a) distanciamse da visão unitária da inteligência; b) discordam do conteúdo e/ou da forma de avaliação clássica das capacidades intelectuais; c) postulam a existência de outros fatores na configuração da inteligência humana; d) esses fatores (que variam segundo a abordagem) seriam, em certa medida, os responsáveis pelo sucesso na vida.

Observando a multiplicidade de enfoques sobre a inteligência, parece bastante oportuno relembrar a metáfora do elefante, resgatada por Humphreys (2003) em sua contribuição no segundo simpósio, para ilustrar a complexidade desse campo de estudos que cada pesquisador tenta abarcar desde sua perspectiva teórica sem, contudo, conseguir fazê-lo de forma totalmente aceitável, adequada e convincente. Para Humphreys (2003, p. 119):

É uma tentação comparar os psicólogos, que tratam da inteligência, com os cegos que, situados ante diferentes partes da anatomia de um elefante, tentavam descrever este animal. Não somente os diferentes psicólogos descrevem a inteligência de distintas maneiras, senão que, alguns deles, também se comportam como cegos que, sem tocar a totalidade da anatomia, especulam acerca do elefante ideal ou das qualidades intrínsecas da "elefanticidade". Iniciar a descrição da totalidade do elefante é um objetivo científico que pode ser alcançado se cada uma das partes interessadas aceita a limitação de sua experiência e deseja colaborar entre si. É preciso ter consciência de que estamos observando o [mesmo] elefante.

Qual é a parte do elefante que compete à Inteligência Emocional analisar? Como a IE pode contribuir à compreensão da "elefanticidade"? Essas respostas já começaram a surgir, mas, por enquanto, elas ainda são aproximativas, incompletas, oscilantes. Certamente, considerando o ritmo de produção na área, dentro de alguns anos essas respostas serão menos hipotéticas e mais constatáveis. Não obstante os escassos anos de existência (menos de duas décadas), o construto da IE superou o interesse popular e tem se consolidado na esfera científica.

Atualmente, o campo da IE conta com uma sólida base teórica proporcionada por diferentes linhas de pesquisa, das quais se originaram os modelos teóricos disponíveis, os instrumentos de avaliação, alguns deles empiricamente corroborados. Foi tema monográfico de conceituadas revistas de divulgação científica, como, por exemplo: Emotion (2001, vol. 1), Psychological Inquiry (2004, vol. 15), Journal of Organizacional Behavior (2005, vol. 26), Psicothema (2006, vol. 18), Ansiedad y Estrés (2006, vol.12/ $\mathrm{n}^{\circ} 2-3$ ). Recentemente, o construto foi debatido no I Congreso Internacional de Inteligencia Emocional, sediado pela Universidade de Málaga (Espanha), em setembro de 2007, do qual participaram mais de duzentos pesquisadores, de diferentes partes do mundo, com o objetivo de: revisar os modelos teóricos existentes, analisar os avanços no que tange à avaliação da IE e mostrar o impacto da IE no campo aplicado. A publicação dos anais do evento dará uma idéia mais fidedigna dos reais avanços na área.

Em um interessante trabalho realizado com o intuito de analisar a importância da IE como novo âmbito de estudos da Psicologia, os pesquisadores Salgueiro, Iruarrizaga e Berrocal 
(2004) proporcionam uma visão aproximada de como se desenvolveu e evoluiu o conceito desde sua aparição, em 1990. Tomando como fonte de informação a maior base de dados internacional de Psicologia (PsychoInfo), os autores revisaram todas as publicações que se referiram à inteligência emocional, na forma de artigo e livro/capítulo de livro. Os resultados indicaram a existência de um progressivo interesse pelo construto, principalmente a partir de 1997, coincidindo com o período em que começa a proliferar a elaboração de medidas de avaliação da IE e a surgirem os primeiros estudos relacionando o conceito com diferentes áreas. Também se constatou que entre os três principais representantes dos Modelos de IE (Mayer e Salovey, 2007; Bar-On, 1997; Goleman, 1995), os que mais publicações realizaram no período analisado foram Mayer e Salovey, tanto se consideradas as publicações individuais como conjuntas, somando um total de 90 trabalhos de sua autoria, em contraste com a diminuta quantidade de publicações de Bar-On (2 livros e ou capítulos) e Goleman (3 livros e ou capítulos). Essa expressiva diferença quantitativa confirma a consolidação e persistência das pesquisas dos autores do conceito de IE no âmbito acadêmico. Quanto à vinculação do conceito IE com outros âmbitos de estudo, observa-se a predominância de quatro áreas aplicadas: Educação (118 publicações); Saúde (73 publicações); Liderança (70 publicações) e Ajuste Social (44 publicações). Os autores concluem que o conceito de IE evoluiu notavelmente nos seus primeiros catorze anos de existência e destacam, como principais contribuições para alcançar esses resultados, as proporcionadas por Mayer e Salovey, tanto no que tange à abordagem teórica, quanto no que se refere aos instrumentos de avaliação de seu Modelo de Inteligência Emocional.

A análise desenvolvida neste artigo mostra que a inteligência constitui um campo de pesquisa instigante, atrativo e fecundo. Há muito que desvendar ainda sobre a sua natureza. Assim sendo, seria naturalmente esperável que qualquer proposta teórica desenvolvida nessa área provocasse reações científicas, sejam elas favoráveis ou contrárias ao que se propõe.

Em linhas gerais, a inteligência emocional tem mobilizado os estudiosos da inteligência. $\mathrm{Na}$ Espanha, por exemplo, a Universidade de Málaga tem se convertido no principal centro de referência da pesquisa em IE nesse país, desenvolvendo uma profícua linha de pesquisa baseada no modelo de aptidões. Além das numerosas contribuições em revistas científicas nacionais e internacionais, da publicação do primeiro manual de inteligência emocional em Espanhol (2007), entre outras obras (Berrocal \& Díaz, 2002, 2004), o grupo de pesquisa malaguenho encabeça um programa de Doutorado em Inteligência Emocional.

No Brasil, estima-se que o best-seller de Goleman (1995) alcançou a cifra de 360 mil exemplares vendidos, segundo informações divulgadas pela revista Mente e Cérebro, em 2007, $\mathrm{n}^{\circ}$ 179, Ano XV, no artigo intitulado "Emoção: a outra inteligência". No entanto, mais que o impacto popular, interessava-nos conhecer o impacto científico da inteligência emocional no ambiente científico brasileiro.

No intuito de explorar o campo da pesquisa em Inteligência Emocional no Brasil, analisamos a produção acadêmica proveniente dos cursos de pós-graduação stricto sensu para averiguar em que medida o construto da IE tem sido objeto de estudo nos programas de Mestrado Profissionalizante (MP), Mestrado Acadêmico (MA) e Doutorado.

Os cursos na modalidade stricto sensu se caracterizam, essencialmente, pela cientificidade, tendo, portanto, uma função dinamizadora na pesquisa nacional. Há, conseqüentemente, um estreito vínculo entre a produção científica e a universidade, determinado por fatores históricos e medidas políticas de fomento ao desenvolvimento nacional, por meio da qualificação docente. Por isso, optamos por explorar a produção científica relacionada com o construto da IE mediante cursos de pós-graduação, ${ }^{2}$ âmbito privilegiado e prioritário da pesquisa brasileira.

\footnotetext{
2 Este estudo constitui uma das etapas de uma pesquisa mais ampla que estamos realizando no programa de Doutorado de Didáctica de la Lengua y la Literatura, na Universidade Complutense de Madrid, com o objetivo de aplicar o construto da Inteligência Emocional ao campo da Lingüística Aplicada ao Ensino e Aprendizagem de Língua Estrangeira (LE).
} 


\section{MÉTODO}

Esta pesquisa, de natureza exploratória, consistiu em revisar sistematicamente a produção científica proveniente dos cursos de pósgraduação no Brasil, abarcando a produção acadêmica (dissertações e teses) proveniente dos cursos de Mestrado Profissionalizante (MP), Mestrado Acadêmico (MA) e Doutorado (D), referente ao período de 1990 (ano de publicação da primeira formalização teórica do conceito) até 2006 (período disponível para consulta no banco de dados selecionado).

Os dados foram consultados no Banco de Teses da Coordenação de Aperfeiçoamento de Pessoal de Nível Superior (CAPES) - uma das principais vias de acesso e divulgação da produção científica do país e que tem como objetivo facilitar o acesso a informações sobre teses e dissertações defendidas junto a programas de pós-graduação do país. Segundo informaçoes divulgadas no Portal de Periódicos, do qual faz parte o Banco de Teses (http://www.periodicos.capes.gov.br/portugues/ index.jsp), o acervo de resumos disponíveis no Banco de Teses, que contava com 285 mil trabalhos defendidos no período de 1987-2004, foi incrementado em $28,5 \%$, com a recente inclusão de 81.341 trabalhos publicados durante os anos 2005 e 2006. O volume das pesquisas cadastradas neste acervo representam uma mostra bastante representativa da produção científica do país.

Como ferramenta de busca, a CAPES disponibiliza a opção "resumos", que permite pesquisar por "autor", "título" e "palavras-chave". Os registros são relativos a trabalhos defendidos a partir de 1987. Os programas de pós-graduação são os responsáveis diretos pelo fornecimento das informações à CAPES e pela veracidade dos dados.

A coleta de dados se realizou no período de 20 a 27/05/2007, de acordo com os seguintes critérios de busca:

Os registros de teses/dissertações localizados, segundo os critérios de busca usados, foram tratados obedecendo-se às seguintes etapas: 1. ${ }^{a}$ leitura e análise das informações contidas nos resumos; 2. ${ }^{\mathbf{a}}$ seleção das pesquisas embasadas no construto da IE; $\mathbf{3}^{\mathbf{a}}$ organização dos dados resultantes da etapa anterior $\left(2^{\mathrm{a}}\right)$ por: ano de defesa da pesquisa (1990 a 2006); nível de estudo (MP, MA, D); instituição de ensino onde se ministrou o curso; teoria de IE que fundamenta a pesquisa; instrumento de avaliação da IE utilizado (nos casos pertinentes); 4. ${ }^{a}$ identificação dos âmbitos de aplicação do construto da IE e classificação dos dados de acordo com as seguintes categorias: 1 . Âmbito teórico; 2. Âmbito laboral; 3. Âmbito da saúde; 4. Ambito educacional; 5. Ambito afetivo.

\section{RESULTADOS E DISCUSSÃO}

Quando realizamos a busca geral no Banco de Teses, foram localizados todos os resumos que incluíam os termos "inteligência" e "emocional", separados ou combinados, perfazendo um total de 66 registros de teses/ dissertações, que foram impressos para análise, seleção e classificação dos trabalhos referentes ao estudo do construto IE.

No primeiro nível de análise dos resumos, foram descartados $50 \%$ dos registros por não estarem (de acordo com as informações contidas nos resumos) diretamente relacionados com o estudo do construto em questão, restando, após essa triagem, apenas 33 pesquisas que tomaram o construto da Inteligência Emocional como objeto de estudo ou como referência teórica para a pesquisa. Vale ressaltar que só foram selecionados os trabalhos que explicitassem a inclusão do construto no resumo, seja pela menção ao conceito, aos instrumentos de avaliação cientificamente reconhecidos ou aos autores/pesquisadores da IE.

O primeiro trabalho de pesquisa sobre a IE, registrado no Banco de Teses, foi defendido em novembro de 1997, como dissertação de Mestrado Acadêmico, realizado em uma instituição privada, num Programa de Psicologia Social. Trata-se de um estudo sobre a relação entre a estrutura de poder e a inteligência emocional na satisfação conjugal. Esse dado indica a possível inexistência de pesquisa sobre a IE, no âmbito acadêmico, durante os primeiros 6 anos de surgimento do conceito. Pode-se também suspeitar que o interesse nessa área tenha sido desencadeado pela influência da publicação de Goleman (1995). A partir do primeiro trabalho, passou a existir uma produção constante, embora flutuante, conforme se pode observar no Gráfico 1. 


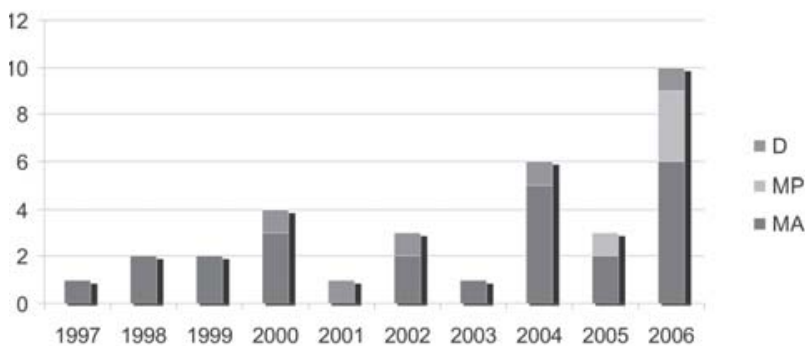

GRÁFICO 1 - Pesquisas relacionadas com o construto da Inteligência Emocional (de 1997 a 2006)

De acordo com os dados, a maior quantidade de trabalhos provém dos cursos de Mestrado (28), em contraste com a produção dos programas de Doutorado (5). Esse contraste, à primeira vista, parece indicar uma grande diferença entre os dois níveis de formação $(85 \%$ $\mathrm{M}$ versus $15 \% \mathrm{D})$. No entanto, se considerados os dados referentes à formação geral de mestres e doutores no país, essa diferença torna-se menos chamativa e se aproxima aos percentuais aproximados de mestres $(28.000 / 77 \%)$ e doutores $(8.000 / 23 \%)$ formados anualmente no país, desde 2003.

Quanto à comparação da produção por tipo de instituição de ensino, causa certa estranheza a equiparação da produção entre as instituições públicas (16) e privadas (17), já que as instituições públicas têm mais tradição (e predominância) em oferta de programas de pósgraduação. Quando considerada a produção específica por instituição, observa-se uma disseminação da produção entre as 19 diferentes instituições relacionadas. Do ponto de vista quantitativo, a única diferença expressiva que encontramos foi uma relativa concentração de trabalhos defendidos na Universidade de São Francisco (8 pesquisas), observando-se, nela, uma constância da pesquisa na área: 2002 (1), 2004 (4), 2005 (1), 2006 (2). Das 8 pesquisas, 7 foram realizadas no programa de Psicologia e estudaram a validez dos testes, especialmente do modelo de habilidades de Mayer e Salovey (1990, 2007) e 1 foi defendida num programa de Educação. Parece haver, nessa instituição, um interesse especial pelo construto da IE.

Quanto aos âmbitos de interesse, os dados não surpreendem e confirmam as tendências da pesquisa na área. O conceito de IE despertou um especial interesse no âmbito laboral, especialmente no campo organizacional. Quase a metade das pesquisas realizadas (13; 42\%) trataram da aplicação da IE ao âmbito laboral, enfocando predominantemente a liderança. $\mathrm{O}$ segundo âmbito de aplicação de maior interesse foi o teórico $(9 ; 27 \%)$. Nessa categoria, os esforços acadêmicos estiveram voltados para analisar a validade de alguns dos testes para medir a IE (9). As informações disponíveis nos resumos não permitiram identificar, em todos os casos, quais foram os testes analisados. Ainda nesse âmbito, também identificamos 2 propostas de construção de medidas para a avaliação de habilidades da IE. Em menores proporções, a pesquisa em IE foi aplicada ao âmbito da Educação $(6 ; 18 \%)$, da saúde $(3 ; 9 \%)$ e ao afetivo $(2 ; 6 \%)$.

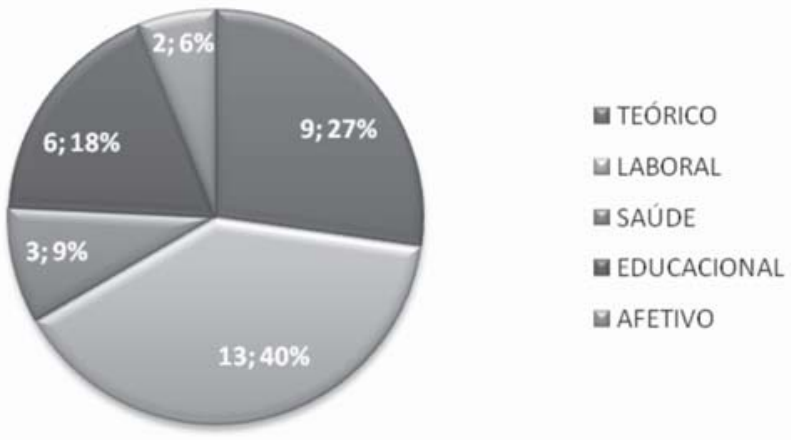

FIGURA 1 - Teses/Dissertações por Âmbito de EStudo

Em linhas gerais, o objetivo desse trabalho foi alcançado. O interesse principal era averiguar o impacto causado pela IE no Brasil, no âmbito científico. Os cursos de pós-graduação são os principais responsáveis pela produção científica do país.

Freqüentemente os estudiosos da IE afirmam, em seus trabalhos de divulgação científica, que o interesse científico pela IE tem sido crescente e generalizado. Pretendíamos explorar esse campo de pesquisa, no intuito de averiguar se essa constatação poderia ser igualmente corroborada com relação à produção do Brasil. No entanto, a aproximação inicial que conseguimos com este estudo indica que a pesquisa em IE, no Brasil, apesar da constância a partir de 1997, ainda está dando seus primeiros passos. Para ampliar o alcance dessa exploração inicial seria interessante ampliar o alcance da revisão, incluindo outras fontes e tipos de produção. 
Para maior aprofundamento acerca dos trabalhos, seria necessária a leitura integral das dissertações e teses. Quando os resumos, cumprem a função de sintetizar, de forma clara e objetiva, a natureza da pesquisa e os aspectos mais relevantes do trabalho, a consulta resulta mais produtiva. Em nosso caso, a tarefa foi dificultada devido à falta de clareza e precisão de vários resumos, assim como a omissão de dados relevantes para o entendimento da proposta. Esse obstáculo impediu a identificação, por exemplo, do(s) modelo(s) teórico(s) tomado(s) como referência para o estudo.

\section{CONSIDERAÇÕES FINAIS}

Nesse artigo, tentamos apresentar uma aproximação teórica e uma aproximação empírica ao construto da Inteligência Emocional. Do ponto de vista teórico, procuramos evidenciar que a inteligência emocional pode ser abordada desde uma perspectiva mais restrita, como uma aptidão, habilidade ou capacidade mental para processar informação de natureza emocional; ou desde uma perspectiva mais ampla, como uma mescla de habilidades cognitivas, variáveis da personalidade e fatores motivacionais. $\mathrm{O}$ primeiro ponto de vista parece cientificamente mais aceitável para tratar a inteligência emocional em consonância com as abordagens emergentes da inteligência humana. Nesse sentido, há evidências teóricas e empíricas para fundamentar a pesquisa na área.

Não há dúvidas de que a popularização do termo gerou grandes repercussões, tanto a nível mediático quanto científico. Não se pode negar que houve - e continua existindo - uma avalanche de publicações, difundindo pseudo-afirmações sobre os benefícios da IE em diferentes âmbitos da vida. Também é certo que muitos dos instrumentos para medir e avaliar o nível de IE, difundidos popularmente, não foram submetidos ao rigor científico da Psicologia e carecem de aval empírico que corrobore sua adequação e eficácia. Mas, se por um lado proliferaram as especulações comerciais, por outro, cresceu também o interesse científico de pesquisadores sérios, empenhados em separar o joio do trigo. Essa divergência tem se revelado necessária e profícua para dilucidar o conceito de IE teórica e empiricamente, o que se pode constatar pelo volume da produção científica dessa linha de pesquisa, à qual tem aderido pesquisadores de diferentes âmbitos de atuação em distintas partes do mundo.

Quanto à aproximação empírica, a pesquisa exploratória, descrita neste artigo, parece indicar que, no âmbito acadêmico, o construto da IE não se destacou como um campo de grande interesse dos pesquisadores brasileiros, sobretudo nos programas de Doutorado. A reduzida produção na área sugere a inexistência de grupos de pesquisa empenhados em desenvolver linhas de pesquisa no campo da Inteligência Emocional, à diferença de outros países (Espanha, Estados Unidos, Inglaterra, Canadá, Dinamarca, entre outros), nos quais a IE tem se consolidado como área de pesquisa da Psicologia. Para obter um panorama geral, portanto mais abrangente, seria necessário ampliar o alcance da pesquisa e revisar, além das teses e dissertações, os artigos científicos.

Não obstante as resistências à aceitação $\mathrm{da}$ inteligência emocional como um novo construto para contribuir à explicação da natureza da inteligência humana, os estudos nessa área têm avançado e dado mostras de maturidade científica. Há um amplo campo de trabalho para aqueles que desejem entender melhor quais são as razões que o coração tem que a própria razão desconbece.

\section{REFERÊNCIAS}

Bar-On, R. (1997). Bar-on emotional quotient inventory (EQ-i): Technical manual. Toronto: Multi Health Systems.

Bechara, A., Tranel, D., \& Damasio, A. R. (2002). Baixa capacidade de julgamento apesar de um alto intelecto: evidências neurológicas da Inteligência Emocional. In R., Bar-On, \& J. D., Parker. (Org.). Manual de inteligência emocional: Teoria e aplicação em casa, na escola e no trabalho. (pp. 148-164). Porto Alegre: Artmed. (Originalmente publicado em 2000).

Berrocal, P. F., \& Díaz, N. R. (2002). Corazones inteligentes. Barcelona: Kairós.

Berrocal, P. F., \& Díaz, N. R. (2004). Desarrolla tu inteligencia emocional. Barcelona: Kairós. 
Berrocal, P. F. \& Pacheco, N. E. (2005). La inteligencia Emocional y la educación de las emociones desde el Modelo de Mayer y Salovey. Revista Interuniversitaria de Formación del Profesorado, 19(3). Recuperado em 15 fev. 2007, www.hezkuntza.ejgv.euskadi.net

Boyatzis, R. E., Goleman, D., \& Rhee, K. S. (2002). Agrupando as competências da Inteligência Emocional: visões do Emotional Competence Inventory. In R., Bar-On, \& J. D., Parker. (Org.). Manual de inteligência emocional: Teoria e aplicação em casa, na escola e no trabalho. (pp. 252-265). Porto Alegre: Artmed.

Cooper, R. K., \& Sawaf, A. (1997). Executive EQ: Emotional intelligence in leadership and organizations. Nova Iorque: Grosst/ Putnam.

Damasio, A. (1996). O erro de Descartes: Emoção, razão e o cérebro humano. São Paulo: Companhia das Letras.

Damasio, A. (2000). O mistério da consciência. São Paulo: Companhia das Letras.

Damasio, A. (2004). Em busca de Espinosa: Prazer e dor na ciência dos sentimentos. São Paulo: Companhia das Letras.

Gardner, H. (1983). Frames of mind: The theory of multiple intelligences. New York: Basic Books.

Goleman, D. (1995). Emotional Intelligence. New York: Bantam Books.

Hedlund, J., \& Sternberg, R. J. (2002). Inteligências em excesso? Integrando as Inteligências Social, Emocional e Prática. In R., Bar-On, \& J. D., Parker, (Org.). Manual de inteligência emocional: Teoria e aplicação em casa, na escola e no trabalho (pp. 110-131). Porto Alegre: Artmed.

Horn, J. (2003). Algunas consideraciones acerca de la inteligencia. In R. J., Sternberg, \& D. K., Detterman (Org.). ¿Qué es 1a inteligencia? Enfoque actual de su naturaleza y definición. (pp. 111-117). Madrid: Pirámide. (Originalmente publicado em 1986).
Humphreys, L. G. (2003). Describiendo al elefante. In R. J., Sternberg, D. K, \& Detterman. (Org.). ¿Qué es la inteligencia? Enfoque actual de su naturaleza y definición. (pp. 118-122). Madrid: Pirámide. (Originalmente publicado em 1986)

LeDoux, J. (2001). O cérebro emocional: os misteriosos alicerces da vida emocional. Rio de Janeiro: Objetiva.

Mayer, J. D., DiPaolo, M. T., \& Salovey, P. (1990). Perceiving affective content in ambiguous visual stimuli: A component of emotional intelligence. In Journal of Personality Assessment, 54, 772-781.

Mayer, J. D., Salovey, P., \& Caruso, D. R. (2002). Inteligência Emocional como zeitgeist, como personalidade e como aptidão mental. In R., Bar-On, J. D., \& Parker. (Org.). Manual de inteligência emocional: Teoria e aplicação em casa, na escola e no trabalho. (pp. 8198). Porto Alegre: Artmed.

Mayer, J. D., \& Salovey, P. (2007). ¿Qué es la inteligencia emocional? In J. M. M., Navas, \& P. F., Berrocal. (Coord.). Manual de inteligencia emocional. (pp. 25-45). Madrid: Anaya. (Originalmente publicado em 1997)

Mestre, J. M. (2003). Validación empírica de una escala para medir la inteligencia emocional, desde un modelo mixto, en una muestra de estudiantes de la Bahía de Cádiz. Tese de Doutorado, Universidad de Cádiz, Cádiz.

Navas, J. M. M., \& Berrocal, P. F. (Coord.). (2007). Manual de inteligencia emocional. Madrid: Anaya.

Pacheco, N. E. \& Berrocal, P. F. (2003). La inteligencia emocional: métodos de evaluación en el aula. Revista Iberoamericana de Educación, 30, Recuperado em 08 de out 2007, da Revista Iberoamerica de Educación: www.rieoei.org.

Salguero, J. M., Iruarrizaga, I, \& Berrocal, P. F. (2004). Inteligencia emocional: desarrollo y evolución del concepto. Boletin de la SEAS, 21, 13-27. 
Salovey, P., \& Mayer, J. D. (1990). Emotional intelligence. In Imagination, Cognition, and Personality, 9, 185-211.

Sternberg, R. J. (1985). Beyond IQ: A triarchic theory of human abilities. New York: Cambridge University Press.

Sternberg, R. J. (1997). Successful intelligence. New York: Plume.

Sternberg, R. J. \& Berg, C. A. (2003). Integración cuantitativa. Definiciones de inteligencia: una comparación de los simposios de 1921 y de 1986. In R. J., Sternberg, \& D. K., Detterman. (Org.). ¿Qué es la inteligencia? Enfoque actual de su naturaleza y definición. (pp. 185-194). Madrid: Pirámide. (Originalmente publicado em 1986)

Sternberg, R. J. \& Detterman, D. K. (2003). ¿Qué es la inteligencia? Enfoque actual de su naturaleza y definición ( 3 a ed.) Madrid: Pirámide. (Originalmente publicado em 1986).

Recebido: 10/01/2008

Received: 01/10/2008

Aprovado: 29/02/2008

Approved: 02/29/2008 